\title{
Apontamentos sobre o Primeiro Ensaio de A Ética Protestante e o "Espírito" do Capitalismo de Max Weber
}

Eduardo José Monteiro da Costa1

\section{Introdução}

A obra A Ética Protestante e o Espirito do Capitalismo (doravante A Ética Protestante) do pensador polímata alemão Max Weber é indiscutivelmente uma das que mais forte influência exerceu no pensamento social e econômico ocidental e brasileiro ao longo do século XX. ${ }^{2}$

Publicada originalmente como dois ensaios, o primeiro em novembro de 1904 e o segundo em junho de 1905, na revista Archiv für Sozialwissenschraft und Sozialpolitk (Arquivo de Sociologia e de Política Social), foi relançada em 1920 com uma redação revista e ampliada, pouco antes da morte de seu autor, como parte do primeiro volume do Ensaios Reunidos de Sociologia da Religião, incorporando a revisão de um autor mais maduro que rebateu algumas críticas formuladas sobre a versão original, sem alterar a tese ou a estrutura originariamente apresentada. Assim, A Ética Protestante, em sua versão derradeira, tornouse uma obra composta por dois ensaios. 0 primeiro, denominado 0 problema, corresponde ao originalmente publicado em 1904 composto por três partes: 1. Confissão religiosa e estratificação social; 2. O "espírito" do capitalismo; 3. O conceito de vocação em Lutero. O objeto da pesquisa. O segundo, A Ética Profissional do Protestantismo Ascético, corresponde ao publicado em 1905 dividido em duas partes: 1. Os fundamentos religiosos da ascese intramundana; 2. Ascese e capitalismo.

Para uma ideia da dimensão e influência desta obra, a Associação Internacional de Sociologia organizou em 1998 o Congresso Mundial de Sociologia em Montreal (Canadá) que realizou uma avaliação crítica da herança sociológica no século XX. No ano anterior (1997), no bojo preparatório do evento, foi realizada uma pesquisa na qual foi solicitado que os membros associados listassem os cinco livros mais influentes em seus trabalhos como sociólogos. ${ }^{3}$ Como resultado A Ética Protestante com 10,3\% dos votos foi eleito o quarto livro mais influente do século.

No Brasil, em 1999 o jornal A Folha de São Paulo realizou uma pesquisa entre uma dezena de importantes intelectuais brasileiros sobre quais seriam os livros de não ficção mais importantes do século

\footnotetext{
1 Doutor em Economia pela Unicamp e professor da Faculdade de Economia e do Programa de Pós-Graduação em Gestão Pública do Núcleo de Altos Estudos da Amazônia (PPGGP/NAEA), ambos da UFPA. Correio eletrônico: ejmcosta@ufpa.br.

2 Dentre os principais autores que, em maior ou menor grau, foram impactados pelo pensamento de Weber podemos listar: Thorsten Veblen, Pierre Bourdieu, Jügen Habermas, Arnol Gehlen, Max Scheler, Karl Jaspers, Leopold von Wiese, Karl Mannheim, Alfred Schütz, Evin Goffman, Eric Voegelin, Norbert Elias, Ernest Gellner e Anthony Giddens. Já em termos do pensamento social brasileiro merecem menção: Gilberto Freyre, Sérgio Buarque de Holanda, Raymundo Faoro, Octávio lanni, Guerreiro Ramos, Juarez Brandão Lopes, Cândido Procópio Camargo, Viana Moog, Mário Wagner Vieira da Cunha, Emílio Willems, Simon Schwartzman, Florestan Fernandes e Celso Furtado (Dias, 1974; D’Aguiar, 2020; Souza, 2020).

${ }^{3}$ A pesquisa obteve resposta de $16 \%$ dos membros associados (455 dos 2.785), que elencaram ao todo 978 livros. Economia e Sociedade, também de Weber, foi eleito o livro mais influente do século XX com $20,0 \%$ dos votos. A pesquisa pode ser acessada no link: https://www.isa-sociology.org/en/about-isa/history-of-isa/books-of-the-xx-century. Acesso em 31/12/20.
} 
$X X .{ }^{4}$ Nesse levantamento, Weber logrou com duas publicações o primeiro e o terceiro lugar entre os 100 livros ou ensaios mais importantes do século XX. Só que no Brasil a obra A Ética Protestante foi eleita a mais importante, tendo Economia e Sociedade ficado na terceira colocação.

Mais recentemente, na onda de "redescobrimento" da cultura como chave para a compreensão das trajetórias de desenvolvimento das nações, a tese seminal de Weber exposta em A Ética Protestante vem sendo paulatinamente resgatada com maior intensidade. ${ }^{5}$ Neste contexto, este artigo, objetivando contribuir para a melhor compreensão da tese exposta em A Ética Protestante, escolheu o primeiro ensaio, publicado originalmente em 1904, denominado O Problema para ser alvo do compartilhamento de apontamentos. Desta forma, está organizado em três partes, alusivas aos tópicos abordados pelo autor, além desta breve introdução e da conclusão. Na primeira disserta sobre a confissão religiosa e estratificação social. Na segunda sobre o "espírito" do capitalismo. E na terceira sobre o conceito de vocação em Lutero. Após, segue-se, como de praxe, a conclusão do artigo.

\section{Afiliação Religiosa e Estratificação Social}

O ponto de partida de Weber em seu primeiro ensaio de $A$ Ética Protestante está na constatação de que a confissão religiosa se mostrava na Alemanha de sua época como um fator determinante para a estratificação social; ponto que ele encara como merecedor de investigação. Sobre isso, segundo Weber (2004), havia no início do século XX na Alemanha, sobretudo no meio católico, um debate sobre a predominância dos protestantes como empresários capitalistas (proprietários do capital), ou mesmo nos postos de trabalho que exigiam mais alta qualificação técnica ou comercial. Conforme 0 autor, isto é comprovado mediante análise das estatísticas ocupacionais extraídas de um trabalho de um orientando seu (Martin Offenbacher), que baliza a parte inicial de seu primeiro ensaio.

Publicado em 1901, o estudo de Offenbacher (Denominação e estratificação social. Um estudo da situação econômica de católicos e protestantes em Baden) apontava que no ano de 1895 a população de Baden na Alemanha possuía maioria católica (61,3\%), seguida pelos protestantes (37\%) e por um percentual residual de judeus $(1,5 \%) .{ }^{6}$ Todavia, ao analisar a receita tributária média sobre rendas de capital segundo estratificação religiosa, constatou que esta se mostrava inversamente proporcional a sua representatividade relativa em termos populacionais: 4 milhões de marcos por mil indivíduos no segmento

\footnotetext{
${ }^{4} \mathrm{O}$ júri foi composto pela seguinte banca: o crítico literário e escritor Modesto Carone, o antropólogo Roberto DaMatta, o físico Rogério Cézar de Cerqueira Leite, o economista Eduardo Giannetti, os historiadores Evaldo Cabral de Mello e Nicolau Sevcenko e os professores de filosofia Maria Sylvia Carvalho Franco, Olgária Matos, Bento Prado Jr. e Renato Janine Ribeiro. A este respeito consultar: Natali (1999).

5 Como exemplos podem ser citados: Fukuyama (1996; 2004), Landes (2004), Sachs (2004), Harrison (2004), Grondona (2004), Pye (2004), Higgins (2005) e Acemoglu e Robinson (2012).

${ }^{6}$ Martin Offenbacker, Konfession und soziale Schichtung. Eine Studie über die wirtschaftliche Lage der Katholiken und Protestanten in Baden (Confissão e Estratificação. Um Estudo Sobre a Condição Económica dos Católicos e Protestantes em Baden), Tübigen e Leipzig (1901), vol. IV, fasc. 5.
} 
judaico, 954 mil marcos por mil indivíduos entre os protestantes e 589 mil marcos por mil indivíduos entre os católicos.

Com base nisto, Weber (2004) afirma que a participação percentual dos protestantes na propriedade do capital, na direção e nos postos de trabalho mais elevados das grandes empresas modernas industriais e comerciais era mais elevada do que a sua representação na população total, atribuindo as causas deste fenômeno a razões históricas, parte delas relacionada com: os recursos patrimoniais historicamente herdados, a diferença em termos de direcionamento educacional e as vantagens da conversão de determinadas cidades ao protestantismo. ${ }^{7}$

Ao mencionar o processo de conversão das regiões economicamente mais dinâmicas ao protestantismo, Weber lança uma pergunta: qual a razão desta predisposição das regiões econômicas mais desenvolvidas a aderirem ao protestantismo? Sem, porém, desenvolver uma resposta, Weber limita-se a afirmar que esta não é tão simples, sobretudo porque a Reforma Protestante representou a troca de uma dominação eclesiástica "extremamente cômoda" da Igreja Católica (intransigente com os hereges, mas indulgente com os pecadores), por outra ainda mais radical ("infinitamente incômoda" e "insuportável") sobre a conduta de vida de uma forma geral, em especial a linha calvinista.

Esta linha calvinista, por sua vez, demonstrou maior diligência no estímulo de seus filhos para a prática de estudos mais correlacionados com "ofícios econômicos" (um dos fatores explicativos para a diferenciação dos estratos sociais entre protestantes e católicos). Mais uma vez, para chegar a esta conclusão, Weber valeu-se das estatísticas levantadas pelo estudo de Offenbacher.

Offenbacher procedeu a um levantamento da confissão religiosa dos alunos nas escolas secundárias de Baden entre os anos de 1885 e 1891, nas quais a frequências não era obrigatória, constatando que a presença de alunos judeus e protestantes, proporcionalmente, era muito mais representativa do que a de alunos católicos (Tabela 1 ). ${ }^{8}$

Tabela 1 - Confissão religiosa no ensino médio, região de Baden (Alemanha)

\begin{tabular}{|l|l|c|c|c|}
\hline \multicolumn{1}{|c|}{$\begin{array}{c}\text { Tipo de Escola de } \\
\text { Ensino Secundário }\end{array}$} & \multicolumn{1}{|c|}{$\begin{array}{c}\text { Protestantes } \\
(\%)\end{array}$} & $\begin{array}{c}\text { Católicos } \\
(\%)\end{array}$ & $\begin{array}{c}\text { Judeus } \\
(\%)\end{array}$ \\
\hline Gymnasien & $\begin{array}{l}\text { Estudo das humanidades, com destaque } \\
\text { para filosofia e línguas clássicas (hebraico, } \\
\text { grego e latim). }\end{array}$ & 43 & 46 & 9,5 \\
\hline Realgymnasien & $\begin{array}{l}\text { Estudo de línguas modernas, matemática e } \\
\text { ciências. }\end{array}$ & 69 & 31 & 9 \\
\hline Oberrealschulen & Matemática e ciências. & 52 & 41 & 7 \\
\hline Realschulen & Escola secundária básica. & 49 & 40 & 11 \\
\hline höhere Bürgerchulen & Atividades comerciais e práticas. & 51 & 37 & 12 \\
\hline
\end{tabular}

\footnotetext{
${ }^{7}$ Sobre a disponibilidade de capital, em parte segundo Weber (2004, p. 30, itálico do autor) explicado pela "posse da riqueza hereditária", afirma o autor: "Justamente um grande número das regiões mais ricas do Reich, mais favorecidas pela natureza ou pelas rotas comerciais e mais desenvolvidas economicamente, mas sobretudo a maioria das cidades ricas, haviam-se convertido ao protestantismo já no século XVI, e os efeitos disso ainda trazem vantagens aos protestantes na luta econômica pela existência."

8 Para Weber (2004, p. 170, itálico do autor) em nota de rodapé 8 do Capítulo 1: "[...] a taxa de freqüência aos estabelecimentos de ensino médio pelos católicos é inferior em quase um terço à sua taxa na população, e é superada em alguns pontos percentuais somente nos Gymnasien clássicos (essencialmente enquanto requisito para os estudos de teologia)."
} 
\begin{tabular}{|c|c|c|c|c|}
\hline Média & - & 48 & 42 & 10 \\
\hline
\end{tabular} Fonte. Elaborado a partir da nota de rodapé 7 do capitulo 1 de Weber (2004). Obs.: A coluna "Enfase" foi incluida para clarificar a compreensões do tipo de estabelecimento de ensino.

Weber, ao analisar estas informações, concluiu que a presença de um maior número de protestantes nos cursos destinados à preparação técnica e para as profissões comerciais e industriais nas suas palavras "para uma vida burguesa de negócios" -, em grande medida decorrente da atmosfera religiosa da região de origem e da "casa paterna", ajuda a explicar o predomínio desta confissão religiosa entre os trabalhadores mais qualificados e mais bem remunerados, bem como nos postos administrativos.

A partir desta constatação, Weber afirma que certas correntes do protestantismo, em uma alusão específica ao calvinismo, acabaram demonstrando inclinação específica para o que ele chamou de "racionalismo econômico"; ao passo que esse fenômeno não pode ser observado entre os católicos. Nesse momento, Weber reafirma o seu interesse em investigar quais teriam sido os elementos conformativos desta peculiaridade confessional que atuaram na direção indicada; apresentando, logo em seguida, a sua hipótese: a ascese intramundana calvinista enquanto um dos principais fatores causais do desenvolvimento industrial e capitalista. ${ }^{9}$

Finalmente, Weber, quase no final do capítulo, após se valer de alguns exemplos para reforçar a ideia de que há uma clara relação entre protestantismo e "espírito de trabalho" e de "progresso", lança duas importantes observações; a primeira mais perceptível ao leitor, e uma segunda que pode passar despercebida daqueles que não têm maior proximidade com o conjunto teórico desenvolvido por Weber noutras obras. A primeira, feita inclusive em aditamento na versão derradeira, é a de que não são todas as denominações protestantes que operam no sentido de favorecer o desenvolvimento do "espírito" capitalista, mas especificamente a sua linhagem calvinista. A segunda é a de que, mesmo ele tendo restringido o seu objeto de pesquisa à influência do protestantismo ascético na modelagem do "espírito" do capitalismo (ao menos nesta obra), não é adequado relacionar processos históricos com explicações monocausais, deixando muito claro que em sua perspectiva não há uma correlação unívoca entre protestantismo e capitalismo.

\section{0 "espírito" do capitalismo}

A segunda parte do ensaio pode ser considerada como o tópico central da tese apresentada (ao menos no primeiro ensaio), sendo que muitos elementos epistemológicos importantes para a compreensão mais perspicaz do texto não estão explícitos em sua leitura, porém contribuem sobremaneira para a compreensão da tese e dos argumentos desenvolvidos, tais como: a influência do filósofo neokantiano alemão Heinrich Richkert (1863-1936), em especial no tocante ao indivíduo histórico enquanto categoria

\footnotetext{
9 Há, neste sentido, para Weber (2004, p. 36) um "[...] íntimo parentesco entre estranhamento do mundo, ascese e devoção eclesial, por um lado, e participação na vida de aquisição capitalista, por outro."
} 
analítica; e a utilização do recurso do tipo ideal, no caso Benjamin Franklin (1706-1790), como expressão deste indivíduo histórico motriz. ${ }^{10}$

\subsection{0 indivíduo histórico e a influência de Heinrich Richkert}

Weber inicia a segunda parte do primeiro ensaio de $A$ Ética Protestante destacando a utilização do termo "espírito do capitalismo" no título de seu estudo, momento em que lança um questionamento: "O que se deve entender por isso?" (WEBER, 2004, p. 41).

No esboço para elucidar a questão, ainda que provisoriamente, alerta que tal conceito precisa ser percebido como uma "individualidade histórica" (ou seja, um conceito histórico); e, por isso, caracterizado por sua complexidade (um "complexo de conexões"). Assim, somente pode ser desvelado parcialmente (jamais em sua completude), por intermédio de seu significado cultural mediante análise histórica capaz de expor progressivamente os elementos eleitos como pertinentes para o seu desiderato.

Weber, com isto, clareia dois pontos importantes em sua análise. O primeiro é que existem traços desse "espírito" que não serão abordados por ele em seus ensaios, posto não serem pertinentes para o desiderato proposto. Essa observação é importante para que não se cometa o equívoco de reduzir 0 "espírito" do capitalismo weberiano a uma única dimensão, ignorando as próprias advertências de Weber. O segundo é que apenas na conclusão de sua pesquisa, dada à natureza epistemológica de construção de "indivíduos históricos", terá condições de apresentar o conceito de forma mais ampla. Esta é uma percepção importante para a leitura e compreensão da estrutura dos dois ensaios.

Após estabelecer estas advertências, cabe, neste momento, salientar um aspecto importante. Apesar de Weber não tecer nenhuma referência, é perceptível que o seu processo epistemológico carrega de forma evidente a influência do pensamento do filósofo Heinrich Richkert, que estabelecia que a cultura era uma totalidade no "espírito" (Geist) em movimento; um conjunto de fenômenos alheios ao universo da natureza, investido de sentido e possuidor de significados para o todo social no qual se origina. ${ }^{11} \mathrm{~A}$ cultura, nesta perspectiva, é, portanto, resultante de um fenômeno histórico - produto de instituições religiosas, políticas, jurídicas, artísticas e científicas - que estabelece valores que se convertem em forças coletivas de caráter normativo e que definem a teleologia de uma sociedade e de uma época. ${ }^{12}$

Para Richkert é através da utilização deste conceito de cultura que a História adquire caráter de ciência. Dito de outra forma: a História é, em síntese, uma ciência da cultura humana que tem como objeto a análise de fenômenos que se tornam singulares na medida em que são investidos de valor (significado).

\footnotetext{
10 Outro elemento importante para a compreensão do conteúdo exposto é a influência do Romantismo Alemão e a interlocução que Weber estabeleceu com as ideias de Georg Simmel e Werner Sombart. Porém, estes elementos extrapolam a proposta apresentada neste artigo, merecendo uma análise em separado.

11 A respeito do pensamento de Heinrich Richkert e sua influência em Max Weber recomenda-se: Mata (2006); Whimster (2009); Oliveira (2010); Campos (2011); Jahnke (2014); Precioso; Ricetto (2015).

12 A este respeito, a obra de Heinrich Rickert que exerceu mais forte influência foi Ciência da Cultura e Ciência da Natureza publicada em 1899. Já a expressão "indivíduo histórico" foi apropriada por Weber de Os limites da formação de conceitos nas ciências naturais publicado em 1902.
} 
Consequentemente, o desafio para a compreensão do sentido de um todo social em determinado contexto histórico perpassa pela apreensão do sentido de ação individual do agente histórico condicionado por valores - cabendo ao intérprete escolher apenas o que é essencial na realidade efetiva.

A partir dai é claramente perceptível que $A$ Ética Protestante está, em sua estrutura e construção, totalmente embebida com esta visão epistemológica (percepção) que traz para o centro da análise a importância de se identificar, para a compreensão dos fenômenos sociais históricos, o indivíduo histórico que atuou como força motriz de fenômenos sociais mais amplos. É em função disto que é possivvel afirmar que Heinrich Richkert é um personagem que apesar de oculto (não citado explicitamente) se torna fundamental para a lógica epistemológica de A Ética Protestante.

\subsection{Benjamin Franklin como expressão do indivíduo histórico motriz}

Weber (2004) identifica o protestante calvinista (ascético) como o sujeito histórico motriz de forças societárias importantes, se lançando no desafio de descrever os seus valores e a sua ética peculiar; e, com isto, o sentido de sua ação individual e, consequentemente, cultural e social. ${ }^{13}$ Com este propósito, seleciona Benjamin Franklin como referência para a modelagem de um tipo ideal de um indivíduo histórico, possuidor de uma essência empreendedora e de virtudes específicas, personificação de uma ética matizada de uma conduta de vida que encara o trabalho de forma sistemática e como dever; contraponto do tradicionalismo econômico medieval pré-capitalista e expressão máxima do "espírito" do Capitalismo.

Contudo, antes de abordar a caracterização que Weber (2004) elabora de Franklin como representação do tipo ideal, convém clarear um pouco mais este recurso epistemológico.

\subsubsection{A análise compreensiva e o tipo ideal como recurso epistemológico}

Em termos epistemológicos Weber se notabilizou por sua análise compreensiva da sociedade, expressa no pressuposto de que toda ação social é fundada em um ato intencional dos indivíduos (num motivo, numa racionalidade), e pela utilização do tipo ideal como recurso analítico.

Ao analisar a causalidade dos fenômenos sociais, Weber entende que a realidade concreta das relações sociais implica em inesgotáveis possibilidades, algo, portanto, impossível de ser perscrutado pelo olhar analítico individual, cabendo ao intérprete à eleição de determinada fração da realidade para ser estudada compreensivamente. Ou seja, sendo a sociedade um sistema aberto, todo fato social se constitui como um feixe de infinitas possibilidades (de resultados imprevisíveis). Portanto, ao combater a explicação monocausal dos fenômenos sociais, dentro de uma perspectiva pluridimensional (multicausal) - em um claro contraponto ao materialismo histórico e dialético -, colocava como questão importante a explicação

${ }^{13}$ Não por acaso, adverte em sua argumentação que a apreensão conceitual definitiva do termo "espírito" do capitalismo somente será possível na conclusão da investigação. 
da forma como os indivíduos que vivem sob diferentes estruturas civilizacionais atribuem sentido às suas vidas.

Weber não nega a importância das determinações econômicas, porém não as torna único vetor explicativo da dinâmica social. Indo mais além, para ele até mesmo as atividades econômicas precisam ser compreendidas por meio do sentido que os indivíduos dão as suas ações, a sua conduta de vida (Lebensführung). E, ao compreender esta conduta de vida e as motivações das ações individuais é possível abstrair um curso para a história (SAINT-PIERRE, 2004; HERVIEU-LÉGER; WILLAIME, 2009).

Essa leitura fenomenológica da sociedade, é importante repisar, acabou tendo importante rebatimento no legado metodológico weberiano, que se baseou na busca pela ênfase no comportamento do indivíduo como importante categoria para a compreensão social e na utilização do tipo ideal como recurso.

Na medida em que a ordem social é resultante de múltiplas conexões de sentido, estabelecidas pelos indivíduos, Weber (2004) elege a fração da sociedade que passa a estudar compreensivamente. 0 motor da história se centra, portanto, na conexão de sentidos que os indivíduos estabelecem em suas ações sociais e em suas múltiplas esferas de atuação.

Nesta senda, toda a ação individual é motivada quer por uma racionalidade, possuindo objetivos extrínsecos e valores intrínsecos (hábitos, costumes e crenças), ou por impulsos momentâneos de consciência do ator social. Convém, assim, insistir, as atitudes médias dos indivíduos são ao fim e ao cabo expressão de suas múltiplas conexões de sentidos, não havendo desta forma uma ordem social imanente ou uma linearidade histórica determinada.

É justamente como recurso heurístico para compreender os fenômenos sociais e econômicos que Weber se apropria da metodologia do tipo ideal; construído com base em uma imputação causal e numa significação cultural assentada em valores sociais estabelecidos, se valendo de manifestações coletivas de uma sociedade na qual o indivíduo está imerso. ${ }^{14}$

\subsubsection{Benjamin Franklin, o tipo ideal: expressão do indivíduo histórico motriz}

Um bom exemplo da aplicação do tipo ideal como recurso é encontrado na caracterização do calvinista ascético de $A$ Ética Protestante, elegendo Benjamin Franklin como uma abstração analítica que auxilia Weber (2004) na compreensão de uma cosmovisão específica, no estabelecimento de conexões de sentido e relações entre esferas de atuação, bem como na modelagem da essência do que ele denominou de "espírito" do Capitalismo.

\footnotetext{
14 O recurso epistemológico do tipo ideal é apropriado por Weber a partir das influências originárias de Karl Bücher, da Escola Histórica Alemã (doravante apenas escola histórica), e dos historiadores Jacob Burckhardt e Theodor Mommsen. Trata-se de um recurso de abstração que estabelece uma espécie de "caricatura" do objeto alvo de análise, acentuando as suas principais características culturais distintivas, porém tendo clareza de que o mesmo é uma mera abstração analítica (uma utopia), que não existe concretamente em sua forma pura, muito menos dá conta da totalidade dos fatos sociais.
} 
Franklin era um vulto histórico bastante conhecido, tanto nos Estados Unidos quanto na Europa e em outras partes do mundo, por ter tido grande protagonismo como homem público, sendo considerado um dos pais fundadores (founding fathers) dos Estados Unidos e um dos cinco redatores da Declaração de Independência (1776). Esta imagem foi reforçada pela sua célebre autobiografia e por seus diversos escritos, como, por exemplo, A sciencia do bom homem Ricardo, ${ }^{15}$ uma coletânea de provérbios, alguns de sua autoria, que se tornou sucesso editorial, possuindo, inclusive, na perspectiva de alguns analistas, um importante papel na formação da mentalidade capitalista, e que contém, para Weber (2004, p. 42), "em pureza quase clássica" aquilo que lhe interessava demonstrar.

Weber teve acesso a esta obra, tanto que lança mão de uma série de extratos com os objetivos de estabelecer a personificação de seu sujeito histórico (tipo ideal) e realçar as suas virtudes utilitárias:16 "Lembra-te que tempo é dinheiro", "crédito é dinheiro", "dinheiro é procriador por natureza é fértil", "bom pagador é senhor da bolsa alheia", "nada pode contribuir mais para um jovem subir na vida do que pontualidade e retidão em todos os seus negócios". ${ }^{17}$ Como mencionado, para Weber estas advertências morais acabam se tornando de cunho utilitarista: "[...] a honestidade é útil porque traz crédito, e o mesmo se diga da pontualidade, da presteza, da frugalidade também, e é por isso que são virtudes" (WEBER, 2004, p. 45, itálicos do autor).

Franklin, enquanto vulto histórico e expressão do indivíduo histórico que Weber procurava caracterizar, foi propositalmente selecionado com o objetivo de enfatizar as virtudes morais de uma cultura protestante, em especial de sua linhagem calvinista, base da colonização originária norte-americana. ${ }^{18}$ Nesse sentido, dentre as virtudes que são enaltecidas nos diversos capítulos de $A$ sciencia do bom homem Ricardo, bem como na autobiografia de seu autor (FRANKLIN, 2019), podem ser mencionadas: ordem, limpeza, tranquilidade, castidade, resolução, silêncio, justiça, sinceridade, humildade, obediência, temperança; e, em especial, trabalho, ascese, frugalidade, moderação, poupança e aplicação.

Para Weber as virtudes deste indivíduo histórico são a expressão de uma ética revelada metafisicamente. Um Leitmotiv do Capitalismo que estabelece o acúmulo de dinheiro moderado por disciplina e autocontrole do corpo e do espírito - se preservando da busca da felicidade (eudemonismo) e da busca pelo prazer (hedonismo) - como o bem maior (summum bonum) que um indivíduo pode lograr. ${ }^{19}$

\footnotetext{
${ }^{15}$ A obra A sciencia do bom homem Ricardo foi elaborada a partir do Almanaque do Pobre Ricardo, anualmente publicado por Benjamin Franklin entre 1732 e 1758. Sobre obra em tela recomenda-se ver: Sales; Bonfim (2013); Sales (2014); Arriada; Tambara; Duarte (2015).

${ }^{16}$ Os extratos apresentados por Weber são basicamente do segundo e terceiro capítulos do $A$ sciencia do bom homem Ricardo, respectivamente Dicas necessárias para aqueles que querem ser ricos (1936) e Conselhos para um jovem comerciante (1748).

${ }^{17}$ A este respeito ver Weber (2004, pp. 42-44, itálicos do autor).

18 De acordo com Sales (2014), o Almanaque do Bom Homem Ricardo, dada a sua ampla circulação e fácil entendimento dada a linguagem do senso comum, foi bastante influente na educação da população norte-americana. ${ }^{19}$ Conforme Weber (2004, pp. 46-47): "O ser humano em função do ganho como finalidade de vida, não mais o ganho em função do meio destinado a satisfazer suas necessidades materiais. Essa inversão de ordem, por assim dizer, 'natural' das coisas, totalmente sem sentido para a sensibilidade ingênua, é tão manifestamente e sem reservas um Leitimotiv do capitalismo, quanto é estranha a quem não foi tocado por seu bafo."
} 
Esta ética, transcendente e irracional para os não religiosos, ${ }^{20}$ se constitui ao mesmo tempo "uma revelação de Deus" que se torna utilitária para o indivíduo. Foi, assim, procurando desvelar a origem desta ética comportamental que Weber encontrou na formação colonial calvinista herdada nos Estados Unidos a hipótese que passa a ser trabalhada em sua argumentação. ${ }^{21}$

Para Weber (2004) o "espírito" do Capitalismo, mesmo que em um delineamento ainda que provisório, nada mais seria do que a expressão de uma conduta de vida racional-metódica expressa por uma ética sistemática do trabalho movida por valores em relação ao mundo e um propósito; expressão de um dever que ambicionava o ganho de forma legítima e racional. Ou seja, uma conduta ética de vida moldada, ainda que subliminarmente, por impulsos religiosos derivados da ascese cristã (de viés calvinista). ${ }^{22}$

Whimster (2009), nesta mesma linha, chama atenção de que Weber sugere uma continuidade entre Franklin e o puritanismo, uma vez que o pai de Franklin era um calvinista. ${ }^{23}$ Deste modo, havia uma predisposição mental baseada na crença da predestinação que influía na forma de condução da vida, com o calvinismo fornecendo um importante "gene cultural" que moldou a forma de comportamento no nascente capitalismo dos Estados Unidos embutindo a ideia do dever profissional como vocação.

Neste ponto convém, sem o risco de perder a direção, inserir duas importantes observações interligadas que são feitas por Weber. A primeira é que de forma sucinta estabelece uma crítica ao materialismo histórico que coloca a superestrutura social como um mero reflexo da base de reprodução material da sociedade. Para Weber a conduta de vida que moldou o "espírito" do Capitalismo, antes de se firmar como elemento cultural (e, portanto, histórico), precisou emergir não apenas em indivíduos singulares, mas, sobretudo, como expressão de um grupo de pessoas. A segunda, em conexão com a primeira, é que o referido "espírito" do Capitalismo, no sentido por ele adotado, ao menos na terra natal de Benjamin Franklin, "[...] existiu incontestavelmente antes do 'desenvolvimento do capitalismo"' (WEBER, 2004, p. 48, itálico do autor). Neste caso, arremata Weber (2004, p. 49): "[...] a relação de casualidade é de todo modo inversa àquela que se haveria de postular a partir de uma posição 'materialista'." Em síntese, para Weber, essa ética social, inerente da cultura capitalista, porém não a sua única determinante,

\footnotetext{
${ }^{20}$ Na perspectiva de Weber (2004), para o irreligioso a conduta ascética intramundana de alguém dotado de motivações transcendentais seria, em perspectiva, irracional.

${ }^{21}$ Weber (2004), nesse sentido, menciona a importância da influência que o pai de Benjamim Franklin, Josiah Franklin, um "calvinista estrito", teve na conformação de sua visão de mundo.

${ }_{22}$ Cabe, contudo, estabelecer uma ressalva neste ponto advertindo que tinha clareza de que o conceito de "espírito" do Capitalismo, justamente por ser um conceito histórico, portanto conformado por múltiplas conexões de sentido e, justamente por isto, complexo, não pode ser simplesmente resumido desta forma. A citação de Weber (2004, p. 42, itálico do autor), neste sentido, se torna conveniente: "[...] não se pode ou não se deve necessariamente entender por 'espírito' do capitalismo somente aquilo que nós apontaremos nele como essencial para a nossa concepção."

23 O próprio Weber (2004) destaca a influência do pai de Benjamin Franklin em sua formação, enfatizando que 0 mesmo relatava os ensinamentos de seu pai com destaque para o provérbio bíblico que o seu pai sempre lhe recitava em sua juventude: "Você já observou um homem habilidoso em seu trabalho? Será promovido ao serviço real; não trabalhará para gente obscura" (Pr. 22.29, NVI).
} 
antecedeu o próprio Capitalismo Moderno, não sendo, portanto, resultante das relações históricas materialistas, mas sim de relações históricas culturais. ${ }^{24}$

Com base nisso, após delinear (ainda que provisoriamente) o que entendia por "espírito" do Capitalismo, Weber destaca que o mesmo teve que para se impor "[...] travar um duro combate contra um mundo de forças hostis" (WEBER, 2004, P. 49), tendo no tradicionalismo (também enquanto conceito histórico) uma ética que precisou ser superada.

\section{0 conceito de vocação em Lutero}

\subsection{A concepção de vocação}

Weber inicia a terceira parte do primeiro ensaio explanando a cerca da concepção de vocação, que, em sua análise, se expressa numa prática de autocontrole sistemático na busca de objetivos ou propósitos constantes; uma expressão da racionalidade embutida na lógica do Capitalismo Moderno (BARBALET, 2000). ${ }^{25}$ Para isso, destaca a conotação religiosa embutida nas palavras Beruf (alemão) e calling (inglês) que trazem em si um significado metafísico (que transcende ao material e se apresenta como um chamamento divino). ${ }^{26}$

Weber enfatiza que enquanto nos povos de predominância protestante o conceito de vocação assume caráter transcendental inexiste expressão que apresente matriz (significado) semelhante nos países de predominância católica (e nem na Antiguidade clássica), o que o leva a afirmar que a palavra e o seu entendimento como um chamamento transcendente é produto direto da Reforma Protestante. ${ }^{27}$ Para ele, a Reforma produziu importantes mudanças na cultura da sociedade europeia, algumas imprevistas ou não intencionais, incluindo a percepção de dever existencial, em especial nas atividades "seculares" desenvolvidas (trabalho/ocupação), a ponto de gerar neologismos, tal como aconteceu em especial com a palavra vocação: Beruf (alemão), beroep (holandês), calling (inglês), kald (dinamarquês) e kallelse (sueco). Em suma, sob a égide da Reforma o conceito de vocação se consolida como uma importante chave epistemológica para compreensão da ação social dos atores modernos, ${ }^{28}$ influenciando, por meio de ações teleológicas (a existência de um propósito existencial), decisivamente na prática da racionalidade - base da vida burguesa e do Capitalismo Moderno.

Aqui cabe um alerta. Não é incomum encontrarmos leituras equivocadas a respeito da tese apresentada por Weber. Estas, muitas vezes afirmam que para ele o protestantismo está na origem do

\footnotetext{
${ }^{24}$ Weber (2004) enfatiza que a ordem econômica capitalista se materializa como um imenso cosmo, um imutável envoltório, no qual o indivíduo nasce e tem de viver.

25 Para Whimster (2009), o capítulo 3 do primeiro ensaio, "A Concepção de Lutero do Chamamento", diz respeito quase exclusivamente à hermenêutica. É baseado puramente em exegese e em interpretação textuais.

${ }^{26}$ Conforme corrobora Whimster (2009), Weber desenvolve o argumento de que a ideia de ocupação é religiosa na origem, como indicado pelo conceito de vocação ou chamamento (Beruf).

${ }_{27}$ Convém destacar que das chamadas línguas "antigas" somente a hebraica possuía uma expressão de significado semelhante, melakah (מלאבה) que pode ser traduzida como "ocupação". Esta palavra é uma derivação de lak (לאך), apresentando o sentido de "missão" (enviar, mandar).

${ }^{28} \mathrm{O}$ conceito de vocação torna-se recorrente nos estudos de Weber, a ponto de retornar como elemento central de uma série de palestra proferidas na Universidade de Munique entre os anos 1919-1920 e que acabaram sendo publicadas com os títulos Ciência como vocação e Política como vocação.
} 
Capitalismo. Todavia, uma leitura mais atenta de A Ética Protestante deixa muito claro que Weber não argumenta que o Capitalismo Moderno teve origem na Reforma, e nem mesmo que o "espírito do Capitalismo" foi um resultado direto desta revolução religiosa. Ao contrário, ele estabelece uma clara ressalva, a de que o seu mote de pesquisa não procurava valorar o ideário deste movimento, nem em termos religiosos e nem sociopolíticos, especificando que nem o "espírito capitalista" e nem o Capitalismo (em sua forma moderna), eram produtos diretos deste movimento religioso. 0 seu objetivo era tão somente verificar de que forma as ideias advindas deste movimento se consolidaram como forças efetivas dentro do processo histórico (como anteriormente mencionado sempre eivado por múltiplos feixes de sentidos), contribuindo para a modelagem deste "espírito" e da cultura ocidental moderna. Neste ponto, importante repisar, o conceito de vocação enquanto um claro produto da Reforma se consolida como um elemento da racionalidade presente no Capitalismo Moderno.

\subsection{A visão seminal de Lutero}

Weber (2004), em busca da origem desta cosmovisão, resgata a concepção originária de Martinho Lutero (1483-1546) expressa por sua tradução da Bíblia e pelo uso do termo Beruf (vocação), que em sua perspectiva traz consigo algo de novo; a ideia de que há uma missão dada por Deus, levando a ascese, antes praticada apenas em ambientes monásticos (extramundana), para a prática cotidiana dos santos (intramundana), conferindo, como consequência, ao trabalho um valor transcendental.

Segundo Weber (2004), Lutero foi o primeiro a introduzir a ideia de trabalho como possuindo uma conotação religiosa. Para chegar a esta conclusão se valeu da tradução de determinados textos sagrados (Ben Sirac e das epístolas de Paulo aos Coríntios) - traduções feitas a partir da comparação dos originais em grego com as versões latina, hebraica e outras traduções anteriores - informando que nas versões anteriores a Lutero não havia nas palavras relacionadas a emprego, tarefa ou trabalho nenhuma conotação religiosa (ergon no grego, opus no latim ou mesmo Pflicht no alemão). Estas palavras, contudo, passaram a ser traduzidas por Lutero como Beruf, ensejando, a partir de então, um uso religioso da prática do trabalho relacionado à vocação.

Porém, Weber (2004) apresenta uma ressalva importante, a de que, em que pese isto, Lutero ainda se manteve próximo de uma visão "tradicionalista", próxima do catolicismo romano (tradicionalista, patriarcal e autoritário) e do ideário medieval, que não concebia a ascese intramundana de forma sistemática (REISEBRODT, 2012). Neste ponto, Weber, que era formado dentro do ambiente protestante alemão (considerado naquele momento por muitos como portador do progresso e da razão), ${ }^{29}$ aparta 0 luteranismo do que ele denominou de protestantismo ascético (calvinistas, quakers, batistas e metodistas).

${ }^{29}$ Os pais de Weber eram protestantes. E, conforme a sua biografia, o mesmo chegou a frequentar ativamente 00 Evangelisch-soziale Kongress (Congresso Social Protestante), uma associação fundada em 1890 por teólogos, sociólogos e economistas que estavam preocupados com a questão social e que se tornou um importante fórum de discussão da socialdemocracia. Ao mesmo tempo, colaborou com a revista de matriz liberal-protestante Die Christliche Welt (O Mundo Cristão), tendo mantido um relacionamento muito próximo com Friedrich Naumann (1860-1919), que 


\subsection{A perspectiva calvinista}

A prática do ascetismo intramundano na perspectiva weberiana resultou diretamente da linhagem reformada advinda de João Calvino (1509-1564), que em sua cosmovisão pugnava pela quebra da dicotomia entre sagrado e secular; e por meio da doutrina da predestinação estabeleceu um importante incentivo para a adoração a Deus pelos salvos por meio do exercício diário da vocação (chamado).

Na perspectiva calvinista o ministério salvífico se dá mediante escolha de Deus (predestinação), e a manifestação da graça, do favor de Deus, se expressa por meio do exercício vocacional do eleito, mediante o exercício de uma vida sistemática, racional, objetiva e integral (marca registrada da ética calvinista). Este ascetismo racional intramundano, baseado em uma prova de fé dada por resultados objetivos - rejeitando a adoção de práticas religiosas contemplativas, emotivas ou místicas -, acaba se consolidando, conforme Weber (2004), como uma importante expressão do calvinismo, em especial em seu segmento puritano. ${ }^{30}$

Para chegar a esta conclusão Weber parte da observação da atração especial que os protestantes tinham por atividades relacionadas ao mundo dos negócios e pelo estabelecimento de uma organização (racionalidade) rígida das tarefas cotidianas; expressão de sua ética religiosa. Ao pesquisar as raízes desta ética chega à Confissão de Westminster (1647) e nos sermões do ministro puritano Richard Baxter (1615-1691). A este respeito Kalberg (2010, p. 47) afirma:

Para Weber, as revisões introduzidas por Baxter nas ideias calvinistas tinham a
intenção de eliminar as conclusões sombrias que decorriam logicamente da "Doutrina
da Predestinação": se o problema da salvação era a questão urgente dos crentes; se
o indivíduo estava predestinado desde o início à "condição de eleito" pela graça divina,
e se Deus somente escolhera uns poucos para serem salvos, a consequência lógica
era instalarem-se entre os devotos sentimentos de fatalismo, desespero, solidão e
angústia. Reconhecendo que a crueldade desse decreto divino impedia seu apoio
contínuo por parte da maioria dos fiéis, entre outros motivos, Baxter e os "Puritan
Divines" (ministros ou pastores puritanos) fizeram modificações que, segundo Weber,
fundaram a ética protestante.

Ainda conforme Kalberg (2010), Baxter, acompanhando as teses de Calvino, enfatizava que 0 crente não tem condições de conhecer a natureza da decisão divina; porém, o Reino de Deus ao manifestar a Sua glória se materializa através da riqueza, igualdade e prosperidade de seus filhos, sendo, assim, uma expressão da Sua justiça e bondade.

além de pastor e teólogo foi o primeiro presidente do Partido Democrata Alemão e um dos fundadores da República de Weimar.

30 Sob este aspecto Whimster (2009) enfatiza que de certa forma a perspectiva cristã medieval tendia a assimilar 0 sobrenatural ao cotidiano. De forma diferente para o calvinista, em especial para o puritano, isso não era aceito. Nas palavras de Whimster (2009, p. 92): "Seu problema não era tanto atingir, através da mística, do êxtase e das técnicas de perda sensorial e da intensificação que os acompanham, um estado psicológico, mas, antes, assegurar a salvação após a morte." 
Não é difícil perceber que decorre daí a compreensão de que o trabalho constante, metódico e diligente, expressão de uma vocação, assumiu um significado espiritual entre os crentes, auxiliando-os na busca pela santificação. Consequentemente, a prática de uma atividade econômica bem sucedida ao mesmo tempo em que era uma forma de adoração a Deus - superando a visão dualista entre sagrado e secular que predominava na ética econômica tradicional medieval -, era um forte indício da revelação da eleição divina (predestinação), indicando, ao menos psicologicamente, a salvação do crente. ${ }^{31}$

É em virtude disso que Weber enfatiza que na Inglaterra, Holanda e Nova Inglaterra dos séculos XVI e XVII a manifestação do favorecimento (eleição) de Deus era uma questão social imperiosa, o que contribuiu decisivamente para a prática sistemática de uma conduta de vida imersa em princípios éticos, expressão de uma ética protestante assentada no ascetismo intramundano.

Em síntese, enquanto o luteranismo foi importante para introduzir o conceito de vocação (chamamento), o calvinismo foi decisivo para a conformação desta ética particular ao condicionar a manifestação da eleição (salvação), dentro de uma lógica da predestinação, na prática da ascese intramundana; importante para a conformação de uma cultura propícia ao desenvolvimento do Capitalismo Moderno.

\section{Conclusão}

Este artigo teve por objetivo contribuir para a melhor compreensão do texto de A Reforma Protestante, em especial de sua primeira parte, publicada originariamente em 1904 na revista Archiv e intitulada 0 problema. 0 próprio título do ensaio já demonstra cabalmente o seu conteúdo epistemológico ao apresentar uma agenda de pesquisa que o instou a se aprofundar na influência da Reforma Protestante sobre a origem do "espírito" do Capitalismo.

O ponto de partida de Weber é a constatação de que protestantes se destacavam enquanto empresários ou mesmo em postos de trabalho que exigiam mais alta qualificação técnica ou comercial. Para isso, se valeu diretamente do trabalho Denominação e estratificação social. Um estudo da situação econômica de católicos e protestantes em Baden de seu orientando Martin Offenbacher que apontou que em uma Alemanha de maioria católica, judeus e protestantes possuíam relativamente maior participação na renda nacional. Uma adequada explicação para isso, apontada por Offenbacher, era a presença de um maior número de protestantes nos cursos destinados à preparação técnica e para as profissões comerciais e industriais.

Weber, instado por estas informações, passa a buscar explicações para este fato, atribuindo as causas deste fenômeno a razões históricas, parte delas relacionadas com os recursos patrimoniais

31 Outro ponto enfatizado por Baxter, segundo Kalberg (2010), era que a prática de uma atividade de forma contínua e sistemática consistia em uma virtude cristã que contribuía para a elevação da alma humana. 
historicamente herdados, a diferença em termos de direcionamento educacional e as vantagens da conversão de determinadas cidades ao protestantismo.

Após reforçar a ideia de que há uma clara relação entre protestantismo e "espírito de trabalho" e de "progresso", Weber passa a buscar explicações para este "espírito", tema que domina a segunda e mais importante parte do primeiro ensaio. Contudo, antes de sumarizar alguns dos principais aspectos apresentados, bem como destacar outros que são importantes, mas que fogem do escopo aqui apresentado, é forçoso reconhecer que $A$ Ética Protestante não é uma obra de fácil leitura.

A Ética Protestante, ao mesmo tempo em que dialoga permanentemente com autores e obras contemporâneas, foi redigida dentro de uma agenda pessoal de seu autor que estava, ao mesmo tempo, sistematizando elementos epistemológicos que o levariam a conformação da análise compreensiva, e tentando entender melhor a dinâmica e a formação de complexos societários e as razões do surgimento e desenvolvimento do Capitalismo na Europa Ocidental em detrimento a outras partes do mundo. É possível perceber que Weber, como agenda mais ampla e que transcende esta obra, busca compreender o que dotava o ocidente de singularidade(s); sendo que $A$ Ética Protestante acabou se consolidando como um importante passo nesta agenda, complementada por outras obras, com destaque especial para Ensaios Reunidos de Sociologia da Religião (1920), Economia e Sociedade (1922) e História Econômica Geral (1923).

Uma importante influencia na obra de Weber, em especial na segunda parte de seu primeiro ensaio, é o filósofo neokantiano alemão Heinrich Richkert que se notabilizou por ter destacado a cultura como um fenômeno histórico que determina valores sociais que se convertem em forças coletivas de caráter normativo, estabelecendo a teleologia de uma época e de uma sociedade (uma totalidade no "espírito"). Para Richkert, a História é uma ciência da cultura humana, devendo a análise histórica perscrutar os fenômenos sociais singulares que modelam o sentido da ação individual de agentes históricos condicionados por valores. É a partir desta influência que Weber estuda o protestante ascético de linhagem calvinista como sujeito histórico motriz de uma conduta de vida que era a expressão do "espírito" do Capitalismo (ao menos uma parte dele).

Como parte deste desiderato de pesquisa, e entendendo que o "espírito" do Capitalismo era um conceito histórico caracterizado por sua complexidade, Weber selecionou Benjamin Franklin como expressão do tipo ideal deste sujeito histórico com a finalidade de ilustrar os seus valores e a sua ética peculiar (virtudes morais de uma cultura protestante), revelada metafisicamente; bem como o sentido de sua ação individual, cultural e social. Ou seja, Franklin ilustra adequadamente a essência empreendedora e as virtudes específicas de um indivíduo histórico que pugnava pelo trabalho de forma sistemática e como dever; expressão máxima do "espírito" que Weber procurava descrever.

Outros conceitos históricos trabalhados por Weber nesta parte do ensaio são o tradicionalismo e o racionalismo econômico (base da ideia de vocação profissional e de dedicação ao trabalho), que 0 ajudam na conformação das cosmovisões pré-capitalista e capitalista, respectivamente. Weber traz assim à tona o debate sobre a conformação da nova cosmovisão que elevou a compreensão da profissão 
enquanto prática vocacional importante para a ordem econômica do Capitalismo Moderno. Esta argumentação, ao incorporar o conceito de "espírito", expressa uma construção secular mais ampla que fora desenvolvida pela escola histórica a partir da influência do movimento romântico alemão. Ao mesmo tempo, carrega um importante debate de época sobre a origem do Capitalismo Moderno que teve, em especial, nas obras Filosofia do Dinheiro (1900) de George Simmel e O Capitalismo Moderno (1902) de Werner Sombart as principais referências, um debate que, contudo, fugiu ao escopo do que fora apresentado neste artigo.

Finalmente, a última parte do primeiro ensaio traz à baila a discussão do termo vocação como expressão da racionalidade embutida na lógica do Capitalismo Moderno, na perspectiva weberiana uma nítida influência da Reforma Protestante. No limite, o "espírito" do Capitalismo acaba sendo influenciado por determinando exercício vocacional através de uma vida sistemática, racional, objetiva e integral (marca registrada da ética calvinista); ou seja, do ascetismo racional intramundano patrocinado, em especial, pelo calvinismo. A conclusão que Weber chega em seu primeiro ensaio publicado é que a predisposição que os protestantes tinham por atividades relacionadas ao mundo dos negócios e pelo estabelecimento de uma organização (racionalidade) rígida das tarefas cotidianas era uma expressão de sua ética religiosa.

\section{REFERÊNCIAS BIBLIOGRÁFICAS}

ACEMOGLU, Daron; ROBINSON, James. Por que as Nações Fracassam: As Origens do Poder, da Prosperidade e da Pobreza. Rio de Janeiro: Elsevier, 2012.

ARRIADA, Eduardo; TAMBARA, Elomar Antonio Callegaro; DUARTE, Sheila. A Sciencia do Bom Homem Ricardo: Um texto de leitura escolar no Brasil Imperial. Hist. Educ. [Online]. Porto Alegre, v. 19, n. 46, p. 243-259, Maio/ago., 2015.

CAMPOS, Daniel Vasconcelos. O Historicismo em Max Weber. Perspectivas, São Paulo, v. 40, p. 147-175, jul./dez. 2011.

COSTA, Eduardo José Monteiro da. O Pensamento Econômico de Max Weber: Um necessário resgate. $48^{\circ}$ Encontro Nacional de Economia (ANPEC). Brasília: Universidade Católica de Brasília, de 08 a 11 de dezembro de 2020.

D'AGUIAR, Rosa Freire. Celso Furtado - um retrato intelectual. In.: SOUZA, Cidoval Moraes; THEIS, Ivo Marcos; BARBOSA, José Luciano Albino (Orgs.). Celso Furtado: a esperança militante. Vol. 1. [Livro Eletrônico]. Campina Grande: EDUEPB, 2020.

DIAS, F. C. Presença de Max Weber na sociologia brasileira contemporânea. RAE-Revista de Administração de Empresas, v. 14, n. 4, p. 47-62, 1 jul. 1974.

FRANKLIN, Benjamin. Autobiografia. Campinas, SP: Editora Auster, 2019.

FUKUYAMA, Francis. Confiança: as virtudes sociais e a criação da prosperidade. Rio de Janeiro: Roco, 1996.

FUKUYAMA, Francis. Capital Social. In.: HARRISON, Lawrence E.; HUNTINGTON, Samuel P. (Orgs.). A cultura importa: valores que definem o progresso humano. Rio de Janeiro: Ed. Record, 2004.

ISAACSON, Walter. Benjamin Franklin: Uma vida americana. São Paulo: Companhia das Letras, 2015.

GRIGOROWITSCHS, Tamara. Um outro espírito, um outro capitalismo: O papel da economia antiga na tipologia do capitalismo de Max Weber. Tese de Doutorado. Universidade de São Paulo: Faculdade de Filosofia, Letras e Ciências Humanas, 2012.

GRONDONA, Mariano. Uma Tipologia Cultural do Desenvolvimento Econômico. In.: 
HARRISON, Lawrense E. Por que a cultura é importante? In.: HARRISON, Lawrence E.; HUNTINGTON, Samuel P. (Orgs.). A cultura importa: valores que definem o progresso humano. Rio de Janeiro: Ed. Record, 2004.

HERVIEU-LÉGER, Danièle; WILLAIME, Jean-Paul. Sociologia e Religião: Abordagens Clássicas. Aparecida, SP: Idéias \& Letras, 2009.

HIGGINS, Silvio Salej. Fundamentos Teóricos do Capital Social. Chapecó: Argos, 2005.

HODGSON, Geoffrey H. How Economics Forgot History: The problem of historical specificity in social science. London: Routledge, 2001.

JAHNKE, Hans-Richard. O Conceito de Compreensão na Sociologia de Max Weber. Coimbra: Imprensa da Universidade de Coimbra, 2014.

KALBERG, Stephen. Max Weber: uma introdução. Rio de Janeiro: Zahar, 2010.

LANDES, David. Quase toda a diferença está na cultura. In.: HARRISON, Lawrence E.; HUNTINGTON, Samuel P. (Orgs.). A cultura importa: valores que definem o progresso humano. Rio de Janeiro: Ed. Record, 2004.

MATA, Sérgio da. O mito de "A ética protestante e o espírito do capitalismo" como obra de sociologia. Lócus: Revista de História, Juiz de Fora, v. 12, n. 1, p. 113-126, 2006.

MÁXIMO, Mário Motta de Almeida. A Guerra dos Métodos: A visão da Escola Histórica Alemã. XIV Encontro Regional da ANPUH-RIO. Rio de Janeiro, 19 a 23 de julho de 2010.

NATALI, João Batista. O século de Max. São Paulo, Domingo, 11 de Abril de 1999. Disponível em: https://www1.folha.uol.com.br/fsp/mais/fs11049904.htm. Acesso em: 20 de jun. de 2019.

NAUGLE, David K. Cosmovisão: a história de um conceito. Brasília, DF: Editora Monergismo, 2017.

OLIVEIRA, Arilson Silva de. Max Weber: indologia e historicismo na obra weberiana. Revista de História 162, pp. 311-333, $1^{\circ}$ semestre de 2010.

PRECIOSO, Daniel; RICETTO, Petrus Ferreira. Ciência, Método e Conceitualização na Filosofia da História de Heirich Rickert (1899-1905). Revista de Teoria da História Ano 7, Volume 14, Número 2, Novembro/2015.

PYE, Lucian W. "Valores asiáticos": de dínamos a dominós? In.: HARRISON, Lawrence E.; HUNTINGTON, Samuel P. (Orgs.). A cultura importa: valores que definem o progresso humano. Rio de Janeiro, Ed. Record, 2004.

RINGER, Fritz. A Metodologia de Mas Weber. São Paulo: Editora da Universidade de São Paulo, 2004.

SACHS, Jeffrey. Notas para uma nova sociologia do desenvolvimento econômico. In.: HARRISON, Lawrence E.; HUNTINGTON, Samuel P. (Orgs.). A cultura importa: valores que definem o progresso humano. Rio de Janeiro: Ed. Record, 2004.

SAINT-PIERRE. Héctor L. Max Weber: entre a paixão e a razão. Campinas, SP: Editora da Unicamp, 2004. SALES, Tâmara Regina Reis. O Almanaque do Bom Homem Ricardo: práticas educacionais norteamericanas e sua circulação no Brasil oitocentista. Dissertação (Mestrado em Educação) Universidade Tiradentes - (UNIT). Aracaju, 2014.

SALES, Tâmara Regina Reis; Bonfim, Ellen de Souza. Almanaque do Pobre Ricardo: Princípios da Cultura Norte-Americana como Prática Educativa no Brasil. VII Colóquio Internacional "Educação e Contemporaneidade". São Cristovão/SE/Brasil, 19 a 21 de setembro de 2013.

SCHUMPETER, Joseph Alois. História da Análise Econômica. Volume 2. Rio de Janeiro: Centro de Publicações Técnicas da Aliança para o Progresso, 1964.

SCREPANTI, Ernesto; ZAMAGNI, Stefano. Panorama de historia del pensamiento económico. Barcelona: Editora Ariel S.A., 1997.

SOUZA, Jessé de. A atualidade de Max Weber no Brasil. Revista Cult, 2020. Disponível em: https://revistacult.uol.com.br/home/a-atualidade-de-max-weber-no-brasil/. Acesso em 12/06/2020.

WEBER, Max. A Ética Protestante e o "Espírito" do Capitalismo. São Paulo: Companhia das Letras, 2004. WHIMSTER, Sam. Weber. Porto Alegre: Artmed, 2009.

Recebido em 12 de fevereiro de 2021.

Aceito para publicação em 15 de maio de 2021. 


\section{Apontamentos sobre o Primeiro Ensaio de A Ética Protestante e o "Espírito" do Capitalismo de Max Weber}

\section{Resumo}

Recentemente, na onda de "redescobrimento" da cultura como chave para a compreensão das trajetórias de desenvolvimento das nações, a tese seminal de Max Weber exposta em A Ética Protestante e 0 "Espírito" do Capitalismo vem sendo resgatada com maior intensidade. Neste contexto, este artigo, objetivando contribuir para a melhor compreensão da tese exposta nesta obra, escolheu o primeiro ensaio, publicado originalmente em 1904, denominado O Problema para ser alvo do compartilhamento de apontamentos. Desta forma, está organizado em três partes, alusivas aos tópicos abordados pelo autor, que dissertam sobre a confissão religiosa e estratificação social, o "espírito" do capitalismo e o conceito de vocação em Lutero.

Palavras-chaves: Max Weber. Ética protestante. "Espírito" do Capitalismo. Confissão religiosa e estratificação social. Conceito de vocação.

Notes on the First Essay of The Protestant Ethics and the "Spirit" of Capitalism by Max Weber

\section{Abstract}

Recently, in the wave of "rediscovery" of culture as a key to understanding the trajectories of development of nations, Max Weber's seminal thesis exposed in The Protestant Ethics and the "Spirit" of Capitalism has been rescued with greater intensity. In this context, this article, aiming to contribute to a better understanding of the thesis presented in this work, chose the first essay, originally published in 1904, called O Problema, to be the target of sharing notes. Thus, it is organized into three parts, alluding to the topics covered by the author, which discuss religious confession and social stratification, the "spirit" of capitalism and the concept of vocation in Luther.

Keywords: Max Weber. Protestant ethics. "Spirit" of Capitalism. Religious confession and social stratification. Vocation concept.

Classificação JEL: B15; B31; B40. 